\title{
A No-Arbitrage Fractional COINTEGRATION MODEL FOR Futures AND SPOT DAILY RANGES
}

\author{
EDUARDO ROSSI* \\ PAOLO SANTUCCI DE MAGISTRIS
}

\begin{abstract}
The no-arbitrage relation between futures and spot prices implies an analogous relation between futures and spot daily ranges. The long-memory features of the range-based volatility estimators are analyzed, and fractional cointegration is tested in a semi-parametric framework. In particular, the no-arbitrage condition is used to derive a long-run relationship between volatility measures and to justify the use of a fractional vector error correction model (FVECM) to study their dynamic relationship. The out-of-sample forecasting superiority of FVECM, with respect to alternative models, is documented. The results highlight the importance of incorporating the long-run equilibrium in volatilities to obtain better forecasts, given the information content in the volatility of futures prices. (C) 2011 Wiley Periodicals, Inc. Jrl Fut Mark
\end{abstract}

\footnotetext{
The authors thank Giuseppe Cavaliere, Søren Johansen and Katarzyna Łasak for useful comments and suggestions. They also thank the participants to CREATES weekly seminars for helpful comments. Financial support from PRIN 2006 is gratefully acknowledged.

${ }^{*}$ Correspondence author, Dipartimento di economia politica e metodi quantitativi, Via San Felice 5 , University of Pavia, 27100 Pavia, Italy. Tel: 39-0382/986207, Fax: 39-0382/304226, e-mail: erossi@eco.unipv.it.
}

Received February 2011; Accepted September 2011

- Eduardo Rossi is at the Dipartimento di economia politica e metodi quantitativi, University of Pavia, Italy.

- Paolo Santucci de Magistris is at School of Economics and Management, Aarhus University, Denmark. 


\section{INTRODUCTION}

A relevant empirical literature investigates the presence of stochastic trends among financial data. Most of the literature is therefore concentrated on the possibility of common stochastic trends among two, or more, financial variables, motivating a multivariate analysis in terms of cointegration. Whereas many empirical studies have used the theory of cointegration, few have attempted to provide a theoretical explanation for the existence of cointegration between financial time series. Examples of financial justifications for the presence of cointegration are given by the purchasing power parity, see Corbae and Ouliaris (1988), or the present value theory of stock prices, see Campbell and Shiller (1987). Much attention in the empirical finance literature has been devoted to the possibility that two or more assets share the same stochastic trend. An interesting example is the work of Brenner and Kroner (1995), who discuss the intuition as to why a no-arbitrage pricing formula leads to a cointegrated system. A no-arbitrage formula builds a portfolio of assets that replicates a base asset. This suggests that the portfolio must share the same long-run time series properties as the base asset it attempts to replicate. The no-arbitrage pricing formula not only leads to a cointegrated system of assets, but also provides the combinations of the assets required to establish cointegration, see Chow, McAleer, and Sequeira (2000). A stock index and its futures price will be cointegrated if the cost of carry, or the difference between the dividend yield and the interest rate, is stationary. A number of papers have examined the dynamic link between the futures and the cash indexes using cointegrated vector autoregressions. Among others, Dwyer, Locke, and Yu (1996) use a cost of carry model with nonzero transaction costs to motivate the estimation of a nonlinear dynamic relationship between the S\&P 500 futures and cash indexes. They estimate a threshold cointegration model, concluding that arbitrage is associated with a rapid convergence of the basis to the cost of carry. More recently, Pizzi, Economopoulos, and O'Neil (1998) study, with intradaily data, the existence of price discovery and market efficiency in terms of a cointegration relation between spot and futures markets, exploiting their long-run equilibrium relationship represented by the no-arbitrage constraints.

In this study, we show that the no-arbitrage relation between futures and spot prices implies an analogous relation between futures and spot daily ranges, defined as the difference between the daily high and low log-prices, independently of the cost of carry that is negligible. Thus, a simple no-arbitrage rule on the spot and futures prices implies an equilibrium relationship among volatility estimates. At the best of our knowledge, there are no papers exploiting the information contained in the futures volatilities to obtain better forecasts of the spot volatility. In particular, the no-arbitrage condition is used here to 
derive a long-run relationship between volatility measures and to justify the use of a fractional VECM to model their relationship. The analysis of daily S\&P 500 spot and futures log-ranges show that they are both characterized by common level shifts and, when the latter are removed, are fractionally integrated. ${ }^{1}$ Moreover, we show that the series are driven by a common stochastic trend, which implies that they are fractionally cointegrated. Thus, the joint dynamics of futures and spot ranges is studied in terms of fractional cointegration, see Chen and Hurvich (2009) for a review on this topic. Since a key characteristic of two cointegrated variables is that their paths depend on the extent of deviation from the long-run equilibrium, the dynamics of futures and spot logranges is modeled via the fractional cointegration system outlined in Johansen (2008), that is a generalization of the VECM to fractional processes. In the fractional VECM (FVECM hereafter) the integration orders of the endogenous variables and of the error correction terms are allowed to assume non-integer values. The main purpose of this study is to show the importance of exploiting the no-arbitrage equilibrium between futures and spot log-ranges to obtain better forecasts of the spot log-ranges. An out-of-sample forecasting comparison shows the superior forecasting ability of FVECM, which includes an error correction term based on the no-arbitrage restriction, with respect to models which do not account for the long-run equilibrium. This evidence clearly confirms that considering the no-arbitrage condition produces superior long-horizon forecasts.

The study is organized as follows. Section 1 introduces the equilibrium relation between spot and futures ranges induced by the no-arbitrage constraints. Section 2 presents a brief description of the data and the analysis of the long-memory property of range-based volatility estimator, assessing the equality of the integration orders between spot and futures volatility and showing that the two series have to be considered fractionally cointegrated. Given the evidence provided in Section 2, Section 3 introduces the FVECM. Section 4 reports the estimation results. Section 5 provides evidence in favor of the FVECM in terms of forecasting ability and Section 6 concludes.

\section{NO-ARBITRAGE RELATION BETWEEN RANGES}

The no-arbitrage assumption implies that, in a frictionless market, the spot and the futures prices, under risk neutral probability, are related by

$$
F_{t+k \mid t}=S_{t} \cdot e^{k \cdot r_{t+k \mid t}}
$$

\footnotetext{
${ }^{1}$ See Beran (1994) and Palma (2007) for an introduction to fractional processes.
} 
where $r_{t+k \mid t}$ is the return of a risk-free asset that expires in period $t+k$ and $e^{k \cdot r_{t+k \mid t}}$ is referred to as the cost of carry premium. ${ }^{2}$ When the daily volatilities are measured by daily ranges, as in Parkinson (1980), Garman and Klass (1980), Rogers and Satchell (1991), Wiggins (1992), Alizadeh, Brandt, and Diebold (2002), Shou and Zhang (2006), and Jacob and Vipul (2008), the no-arbitrage condition in (1) implies a similar relationship between spot and futures daily ranges. Daily range is defined as the difference between the highest and the lowest log-price recorded in a given day

$$
\begin{aligned}
& R_{t, F}=\max _{\tau} f_{\tau}-\min _{\tau} f_{\tau}, \quad t-1<\tau \leq t \\
& R_{t, S}=\max _{\tau} s_{\tau}-\min _{\tau} s_{\tau}, \quad t-1<\tau \leq t
\end{aligned}
$$

where $f_{\tau}=\log \left(F_{\tau}\right)$ and $s_{\tau}=\log \left(S_{\tau}\right)$ are the natural logarithm of futures and spot price, respectively. As noted by Andersen and Bollerslev (1998), the accuracy of the high-low estimator is close to that provided by the realized volatility estimator based on 2 or 3 h returns. Alizadeh et al. (2002) and Shou and Zhang (2006) shown that the range-based estimators are robust to the presence of microstructure noise. ${ }^{3}$ Combining Equations (1) and (2), the no-arbitrage equilibrium relationship between the forward and spot ranges ${ }^{4}$ is written as

$$
R_{t, F}=R_{t, S}+\mu_{t}
$$

where $\mu_{t}$ is equal to

$$
\mu_{t}=r_{\tau_{\max }}-r_{\tau_{\min }}
$$

for $t-1<\tau \leq t$, where $\tau_{\max }$ is such that $s_{\tau_{\max }}=\max _{\tau} s_{\tau}$, and $\tau_{\min }$ is such that $s_{\tau_{\min }}=\min _{\tau} s_{\tau} \cdot r_{\tau_{\max }}$ and $r_{\tau_{\min }}$ indicate the risk-free rate in correspondence of the highest and lowest log-price in a given day.

Under the hypotheses that the log-price evolves as a random walk in continuous time and that the volatility dynamics is a piecewise-constant process, ${ }^{5}$ an unbiased estimator of daily volatility, $\sigma_{t}$, is given by

$$
\sigma_{t, S}=\lambda_{2}^{-\frac{1}{2}} \cdot R_{t, S}
$$

\footnotetext{
${ }^{2}$ In order to simplify the notation, the reference to the constant time to maturity $k$ is dropped. Therefore, $F_{t}$ will indicate the futures contract opened in $t$ for the period $t+k$, and $r_{t}$ is the risk-free return for the period $(t, t+k)$.

${ }^{3}$ See also Rossi and Spazzini (2009) for an analysis of the finite-sample properties of range-based estimators. ${ }^{4}$ Brandt and Diebold (2006) also make use of no-arbitrage restrictions on daily ranges. However, those restrictions are used to derive closed form expression for time varying return covariances and correlations. ${ }^{5}$ See Alizadeh et al. (2002). This means that the volatility is constant on a given day, but it is stochastic across days.
} 
where $\lambda_{2}=\log (2)$ is a scale factor that is obtained from the second moment of a standard Brownian motion, see Parkinson (1980). Therefore, Equation (3) is recasted as

$$
\sigma_{t, F}=\sigma_{t, S}+\zeta_{t}, \quad t=1, \ldots, T
$$

with $\zeta_{t}=\lambda_{2}^{-\frac{1}{2}} \mu_{t}$. In practice, due to the presence of transaction costs, market imperfections, and measurement errors, an additional error term, $\eta_{t}$ with $E\left(\eta_{t}\right)=0$, should be included on the right-hand side of (6). A sufficient condition for $\zeta_{t}=0$ is that the risk-free rate is constant on a given day. This does not represent a strong restriction, since the intraday variation of the risk-free rate can be considered negligible with respect to the variations in the prices. ${ }^{6}$ The relation (6) between $\sigma_{t, F}$ and $\sigma_{t, S}$ represents an equilibrium condition, on a daily basis, which imposes constraints on the joint dynamics of the two series. Thus, the dynamics of $\sigma_{t, S}$ and $\sigma_{t, F}$ are restricted by the no-arbitrage relation, and are not expected to drift too far apart.

From a dynamic perspective, a well-documented stylized fact is that volatility of financial returns is characterized by long-range dependence, or long memory, see, for instance, Dacorogna, Muller, Nagler, Olsen, and Pictet (1993), Ding, Granger, and Engle (1993), Baillie, Bollerslev, and Mikkelsen (1996), Bollerslev and Mikkelsen (1996), and Granger and Ding (1996). More recently Andersen, Bollerslev, Diebold, and Ebens (2001), Andersen, Bollerslev, Diebold, and Lays (2003) report evidence of long memory in the ex post volatility measures, such as realized volatility. We provide evidence that daily ranges are long-range dependent and can be best approximated by a fractionally integrated process, or $I(d)$, with $0<d<1$. Therefore, given the equilibrium condition in (6), we allow for the possibility that they are fractionally cointegrated, when modeling the long-run relationship between spot and futures ranges. Next section discusses the concept of fractional cointegration and the semiparametric techniques used to estimate the cointegration rank.

\section{LEVEL SHIFTS AND FRACTIONAL COINTEGRATION ANALYSIS}

The data used in this study consist of the daily high and low of spot and futures prices. The spot is the S\&P500 index and the futures is the three months contract on it. The sample covers the period from November 27, 1998 to August 25,2008 , for a total of 2,450 trading days. The time series of daily ranges are then constructed according to (2) and (5). Ranges are transformed in logs.

\footnotetext{
${ }^{6}$ More precisely, the variation $r_{\tau_{\max }}-r_{\tau_{\min }}$ is considered null, namely the risk-free rate is assumed to be constant on daily intervals.
} 


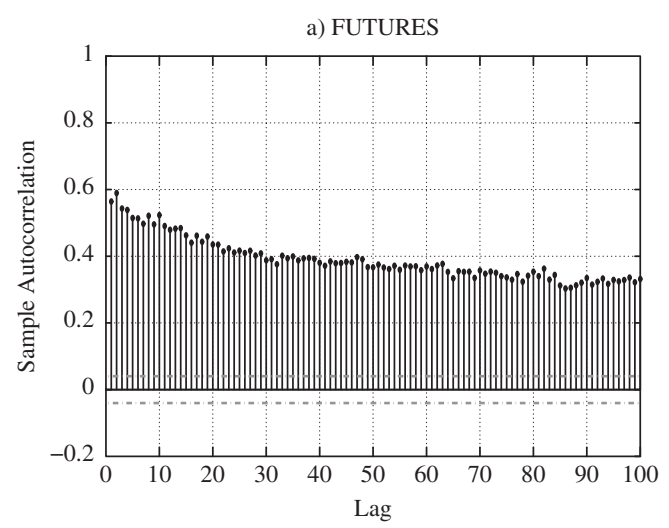

c) DETRENDED FUTURES

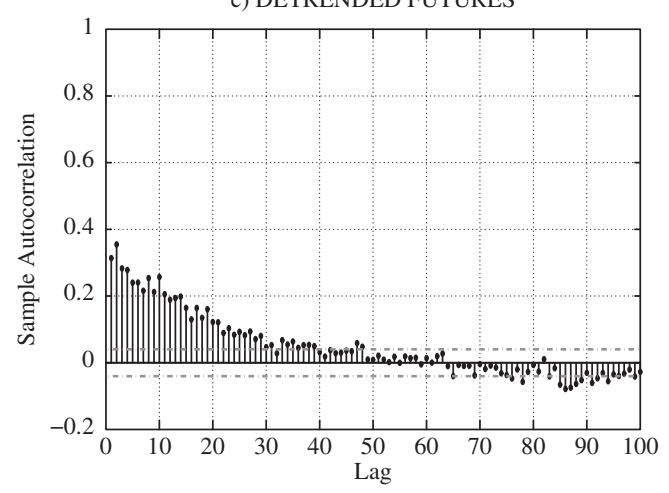

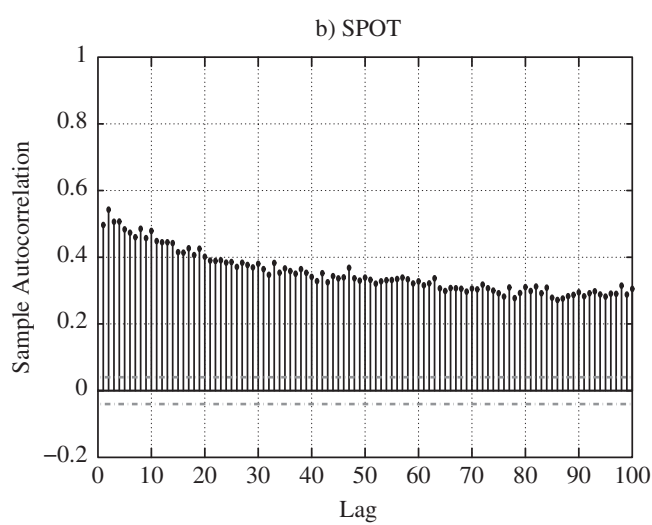

d) DETRENDED SPOT

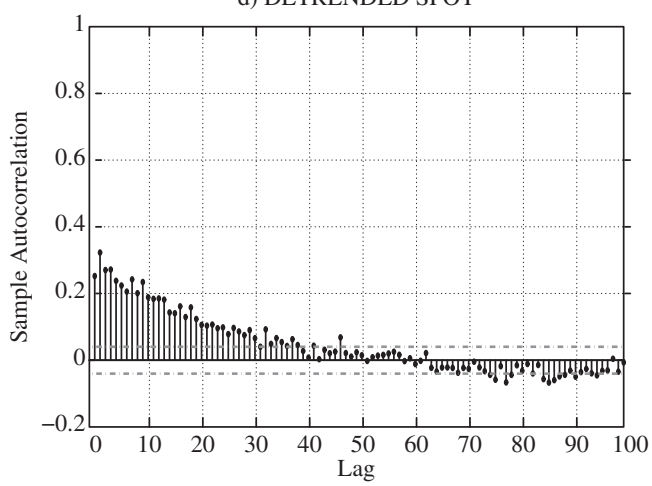

FIGURE 1

Autocorrelogram (ACF) of $\log \sigma_{t, F}$ and $\log \sigma_{t, S}$. Dotted lines are the Bartlett confidence intervals. Detrended indicates the residuals from Bai and Perron (2003) procedure to detect level shifts.

Given the length of the period under analysis, it seems natural to analyze the presence of structural breaks in the series. In fact, as pointed out by Granger and Hyung (2004), the long-memory property of volatility could be induced spuriously by the presence of level shifts. The slow decay of the autocorrelation functions of the futures and spot log-ranges, displayed in Figure 1(a) and 1(b), is clearly supportive of the long-range dependence hypothesis. As noted among others by Granger and Hyung (2004) and Perron and Qu (2010), when a shortmemory process is contaminated by a level shift, then the autocovariance decays slowly and, at long lags, it is dominated by the cumulated shift component, so that it converges to a constant.

An identification problem arises since a similar long-run dependence characterizes the truly long-memory processes. In particular, long memory is defined in terms of decay rates of long-lag autocorrelations, or in the frequency domain in terms of rates of explosion of low-frequency spectra, see Beran (1994). The spectral density $f(\lambda)$ has a pole and behaves like a constant $c_{f}$ times 
TABLE I

Perron and Qu (2010) Test of Truly Long Memory

\begin{tabular}{lllll}
\hline & \multicolumn{2}{c}{ Raw Series } & \multicolumn{2}{c}{ Detrended Series } \\
\cline { 2 - 3 }$c_{1}$ & $\log \sigma_{t, S}$ & $\log \sigma_{t, F}$ & $\log \sigma_{t, S}$ & $\log \sigma_{t, F}$ \\
\hline 1.0 & 0.3050 & 0.0858 & 0.0631 & 0.1572 \\
1.1 & 0.1292 & 0.0384 & 0.2694 & 0.3483 \\
1.2 & 0.0375 & 0.0036 & 0.6753 & 0.9860 \\
1.3 & 0.0693 & 0.0066 & 0.6329 & 0.9924 \\
1.4 & 0.1596 & 0.0174 & 0.4123 & 0.7862 \\
1.5 & 0.0764 & 0.0080 & 0.6853 & 0.9992 \\
1.6 & 0.0147 & 0.0020 & 0.8121 & 0.9729 \\
1.7 & 0.0090 & 0.0019 & 0.6381 & 0.6105 \\
1.8 & 0.0008 & 0.0006 & 0.3442 & 0.4297 \\
1.9 & 0.0007 & 0.0002 & 0.2784 & 0.2904 \\
2.0 & 0.0005 & 0.0003 & 0.2171 &
\end{tabular}

Note. The term Raw Series indicates the original daily log-range series, whereas Detrended Series indicates the residuals from Bai and Perron (2003) procedure to detect level shifts. Table reports the $p$-values of the test statistic in (7). As in Perron and Qu (2010), the bandwidth parameters are chosen as $a=0.5, b=4 / 5$, and $c_{2}=1$, while $c_{1} \in[1,2]$.

$\lambda^{-2 d}$ at the origin. If $d \in(0,1 / 2)$ the process is stationary and presents long memory; instead, if $d \in(-1 / 2,0)$ the process is antipersistent, i.e. it is a shortmemory process. Perron and Qu (2010) propose a test to verify the null hypothesis that the series at hand is a truly long-memory process. Under the null hypothesis, the test statistic is

$$
\sqrt{\frac{24 c_{1}\left[T^{a}\right]}{\pi^{2}}}\left(\hat{d}_{a, c_{1}}-\hat{d}_{b, c_{2}}\right) \stackrel{d}{\rightarrow} N(0,1)
$$

where $\hat{d}_{a, c_{1}}$ and $\hat{d}_{b, c_{2}}$ are obtained with the Geweke and Porter-Hudak (1984) estimator with bandwidth $m_{1}=c_{1}\left[T^{a}\right]$ and $m_{2}=c_{2}\left[T^{b}\right]$, where $[x]$ denotes the largest integer less than or equal to $x$. Perron and Qu (2010) test computed on the raw series, see Table I, rejects the null of truly long memory for both series and for almost all choices of the bandwidth parameter, $c_{1} \in[1,2]$.

Therefore, structural breaks in the log-ranges are identified following the procedure outlined in Bai and Perron (2003). ${ }^{7}$ Not surprisingly, the breakpoints are found to occur on the same dates. From Figures 1(c) and 1(d) clearly emerges the reduction in the persistence, obtained by removing the breaks from the original series. However, the detrended series display true long memory, as shown by the Perron and Qu (2010) test (Table I) which cannot reject the null hypothesis. Our purpose, in this section, is to show that fractional

${ }^{7}$ In the rest of the paper, the residuals from Bai and Perron (2003) procedure are referred as detrended series. 
cointegration between spot and futures log-ranges is not induced spuriously by the presence of common shifts but it is due to their common stochastic trend. ${ }^{8}$

Given the equilibrium relation stated in Equation (6), the possibility of fractional cointegration is tested on both the raw series and the detrended series. Robinson and Yajima (2002) discuss a semi-parametric procedure for determining the cointegration rank, focusing on stationary series. Nielsen and Shimotsu (2007) extend the analysis of Robinson and Yajima (2002), in order to consider cointegration for both stationary and non-stationary variables. In particular, they apply the exact local Whittle estimator of Shimotsu and Phillips (2005) in a multivariate setup, to test the equality of the fractional integration orders, and to estimate the fractional cointegrating rank. In the bivariate case, which is relevant here, the equality of the fractional integration orders is a necessary condition to have non-trivial fractional cointegration.

Since the presence or absence of cointegration is not known when the fractional integration orders are estimated, Nielsen and Shimotsu (2007) propose, as in Robinson and Yajima (2002), a test statistic for the equality of integration orders that is informative in both circumstances, in the bivariate case this takes the form

$$
\hat{T}_{0}=m_{d}(S \hat{d})\left(S \frac{1}{4} \hat{D}^{-1}(\hat{G} \odot \hat{G}) \hat{D}^{-1} S^{\prime}+h(T)^{2}\right)^{-1}(S \hat{d})
$$

where $\odot$ denotes the Hadamard product, $S=[1,-1]^{\prime}, h(T)=\log (T)^{-k}$ for $k>0$, $D=\operatorname{diag}\left(G_{11}, G_{22}\right)$, while

$$
\hat{G}(d)=\frac{1}{m_{d}} \sum_{j=1}^{m_{d}} \operatorname{Re}\left(\mathcal{I}_{X}\left(\lambda_{j}\right)\right)
$$

is a consistent estimator of $G$, the spectral density matrix at the origin, that is singular under fractional cointegration (see Nielsen and Shimotsu, 2007 for more details). $\mathcal{I}_{X}\left(\lambda_{j}\right)$ is the co-periodogram at frequency $\lambda_{j}=2 \pi j / T$ of the fractionally differenced series, $X=\left(\Delta^{d_{F}} \log \sigma_{t, F}, \Delta^{d_{S}} \log \sigma_{t, S}\right)$, with $\Delta^{d}=(1-L)^{d}$, and $\operatorname{Re}(\cdot)$ denotes the real part of the number. ${ }^{9}$ The vector of estimates $\hat{d}=\left(\hat{d}_{F}, \hat{d}_{S}\right)^{\prime}$ is obtained with the univariate exact local Whittle estimator, that makes no assumptions on the presence of cointegration. In particular, each element of the parameter vector $d$ is estimated by minimizing the objective function

$$
Q_{m_{d}}\left(d_{i}, G_{i i}\right)=\frac{1}{m_{d}} \sum_{j=1}^{m_{d}}\left[\log \left(G_{i i} \lambda_{j}^{-2 d}\right)+\frac{1}{G_{i i}} I_{j}\right]
$$

\footnotetext{
${ }^{8}$ In a recent paper, Christensen and Santucci de Magistris (2010) note that the presence of a common level shifts process among two or more $I(0)$ series induces spurious fractional cointegration.

${ }^{9}$ The test statistic in $(8)$ reduces in this case to $2 m_{d}\left(\hat{d}_{1}-\hat{d}_{2}\right)\left(\left(1-\rho_{12}^{2}\right)+2 h(T)^{2}\right)^{-1}$, where $\rho_{12}$ denotes the correlation between the fractionally differenced series.
} 
TABLE II

Fractional Integration Estimation

\begin{tabular}{lccc}
\hline$m_{d}$ & $T^{0.7}=235$ & $T^{0.6}=108$ & $T^{0.5}=49$ \\
\hline Raw Series & & & \\
$d_{F}$ & 0.4797 & 0.5715 & 0.5188 \\
& $(0.0639)$ & $(0.0943)$ & $(0.1400)$ \\
$d_{S}$ & 0.4909 & 0.5636 & 0.5375 \\
$\hat{T}_{0}$ & $(0.0639)$ & $(0.0943)$ & $(0.1400)$ \\
Detrended Series & 0.1653 & 0.0452 & 0.1247 \\
$d_{F}$ & & & \\
& 0.4147 & 0.4851 & 0.2715 \\
$d_{S}$ & $(0.0639)$ & $(0.0943)$ & $(0.1400)$ \\
$\hat{T}_{0}$ & 0.4313 & 0.4753 & 0.3101 \\
& $(0.0639)$ & $(0.0943)$ & $(0.1400)$ \\
\end{tabular}

Note. Exact local Whittle estimates (standard error in parenthesis). The $\hat{T}_{0}$ test statistic is calculated with $h(T)=\log (T)$.

which is concentrated with respect to the diagonal element of the $(2 \times 2)$ matrix $G$, under the hypothesis that the spectral density of $X$ satisfies $f_{X}(\lambda) \sim G$ as $\lambda \rightarrow 0^{+}$. If the variables are not cointegrated, that is the cointegration rank $r$ is zero, $\hat{T}_{0} \rightarrow \chi_{1}^{2}$, while if $r \geq 1, \hat{T}_{0} \rightarrow 0$. A significantly large value of $\hat{T}_{0}$, with respect to $\chi_{1}^{2}$, can be taken as an evidence against the equality of the integration orders.

The cointegrating rank $r$ is estimated by calculating the eigenvalues of the matrix $\hat{G}$, which is obtained with a new bandwidth parameter $m_{L}$. Given $\hat{d}$, computed with $m_{d}$ as bandwidth, the matrix $G$ is then estimated, using $m_{L}$ periodogram ordinates in (9), such that $m_{L} / m_{d} \rightarrow 0$. Let $\hat{\delta}_{i}$ be the $i$ th eigenvalue of $\hat{G}$, it is possible to apply a model selection procedure to determine $r .{ }^{10}$ In the bivariate case,

$$
\hat{r}=\arg \min _{u=0,1} L(u)
$$

where

$$
L(u)=v(T)(2-u)-\sum_{i=1}^{2-u} \hat{\delta}_{i}
$$

for some $v(T)>0$ such that $v(T)+1 / m_{L}^{1 / 2} v(T) \rightarrow 0$. Table I reports the exact Whittle estimates for the raw and detrended series.

The estimates of $d$, in Table II, based on the raw data, are larger than $1 / 2$ when $m_{d}$ is small. Differently, the estimates of the long-memory parameter of the

\footnotetext{
${ }^{10}$ Following Nielsen and Shimotsu (2007) the eigenvalues are calculated using the estimated correlation matrix $\hat{P}=\hat{D}^{-1 / 2} \hat{G} \hat{D}^{-1 / 2}$.
} 
TABLE III

Fractional Cointegration Estimation

\begin{tabular}{|c|c|c|c|c|c|c|}
\hline \multirow[b]{2}{*}{$v(T)$} & \multicolumn{3}{|c|}{ Raw Series } & \multicolumn{3}{|c|}{ Detrended Series } \\
\hline & $m_{L}^{-0.45}$ & $m_{L}^{-0.35}$ & $m_{L}^{-0.25}$ & $m_{L}^{-0.45}$ & $m_{L}^{-0.35}$ & $m_{L}^{-0.25}$ \\
\hline \multicolumn{7}{|c|}{$m_{d}=235, m_{L}=109$} \\
\hline$L(0)$ & -1.7956 & -1.6607 & -1.4368 & -1.7956 & -1.6607 & -1.4368 \\
\hline$L(1)$ & -1.8457 & -1.7762 & -1.6682 & -1.8452 & -1.7778 & -1.6688 \\
\hline$\hat{r}$ & 1 & 1 & 1 & 1 & 1 & 1 \\
\hline \multicolumn{7}{|c|}{$m_{d}=108, m_{L}=50$} \\
\hline$L(0)$ & -1.7099 & -1.5545 & -1.3158 & -1.7099 & -1.4555 & -1.3158 \\
\hline$L(1)$ & -1.8326 & -1.7549 & -1.6355 & -1.8321 & -1.7523 & -1.6350 \\
\hline$\hat{r}$ & 1 & 1 & 1 & 1 & 1 & 1 \\
\hline \multicolumn{7}{|c|}{$m_{d}=49, m_{L}=22$} \\
\hline$L(0)$ & -1.5883 & -1.4118 & -1.1655 & -1.5853 & -1.4118 & -1.1655 \\
\hline$L(1)$ & -1.7836 & -1.6968 & -1.5737 & -1.7826 & -1.6959 & -1.5727 \\
\hline$\hat{r}$ & 1 & 1 & 1 & 1 & 1 & 1 \\
\hline
\end{tabular}

Note. The table reports the value of the function $L(u)$ for different choices of $m_{L}$ and $m_{d^{\prime}} \hat{r}$ is the estimated cointegrating rank.

detrended series fall into the stationarity region for all bandwidths, but the degree of long memory is significantly greater than zero. The $\hat{T}_{0}$ statistic takes values close to 0 in all cases. The equality of the fractional integration orders is consistent with the hypothesis of fractional cointegration and it is robust to the choices of the bandwidth. Furthermore, the analysis of the cointegration rank, in Table III, with three different values for $m_{d}$ and $m_{L}$, confirms the presence of cointegration, since $\hat{r}$ results to be equal to 1 in all cases. Interestingly, the series are fractionally cointegrated even if the presence of structural breaks is removed. As expected, the result of Nielsen and Shimotsu (2007) test confirms that spot and futures log-ranges have the same fractional integration order and are fractionally cointegrated.

\section{THE MODEL}

Given the analysis in the previous section, the joint dynamics of the spot and futures log-ranges is modeled with the FVECM of Johansen (2008), which accounts for the equilibrium relationship induced by the no-arbitrage condition. Contrary to Granger (1986) model, the Johansen (2008) model allows for a Granger representation of cofractional systems in terms of the generalized lag operator $L_{b}=1-(1-L)^{b}$

$$
\Delta^{d} X_{t}=\left(1-\Delta^{b}\right)\left(\Delta^{d-b} \alpha \beta^{\prime} X_{t}\right)+\sum_{j=1}^{K} \Gamma_{j} \Delta^{d} L_{b}^{j} X_{t}+\varepsilon_{t}
$$


where $X_{t}=\left(\log \sigma_{t, F}, \log \sigma_{t, S}\right)^{\prime}$, and $\Gamma_{j}$ are the short-run matrices of parameters. $\varepsilon_{t}$ is an i.i.d. vector sequence with mean 0 and positive-definite covariance matrix $\Omega$. The $(2 \times 1)$ vector $\alpha$ contains the adjustment parameters, while $\beta$ is the $(2 \times 1)$ cointegrating (cofractional) vector, such that $\beta^{\prime} X_{t}$ is fractional of order $d-b$. The parameter $b$ represents the cofractional order, which is the fractional order of the common stochastic trend. A similar model, with the addition of regime switches, has been used by Haldrup, Nielson, and Nielson (2010) to model the congestions on the electricity market. This setup slightly differs from the bivariate model proposed by Duecker and Startz (1998), which is based on a triangular representation of a fractional cointegrated system. This model can be estimated following the method outlined in Sowell $(1989,1992)$. The model in (13) presents several advantages over the traditional cointegration regression and cointegrated bivariate ARFIMA:

- The integration order of the endogenous variables and the fractional cointegration order are defined by two parameters $d$ and $b$, with $0, b \leq d$, that are jointly estimated.

- As outlined in Johansen (2008), the FVECM constitutes a generalization of the well-known triangular model, since in the bivariate case, the assumption $\beta^{\prime} \alpha=-1$ and $\alpha=[1,0]^{\prime}$, implicit in the triangular model, can be relaxed.

- The vector of loading parameters $\alpha$ measures the speed of adjustment to the long-run equilibrium given a short-run departure from that, allowing us to draw conclusions on the relative efficiency of the futures market.

In the FVECM model, the element $\alpha_{i j}$ of the matrix $\alpha$ measures the singleperiod response of variable $i$ to the shock to the $j$ th equilibrium relation. In our analysis, where $r=1$, the parameter $\alpha_{11}$, abbreviated with $\alpha_{1}$, should be negative to guarantee the convergence toward the unique long-run equilibrium implied by the no-arbitrage assumption. The vector $\alpha$ has a clear interpretation as the short-term adjustment coefficient and represents the proportion by which the long-run disequilibrium in the spot (futures) log-ranges is being corrected in each period.

\section{RESULTS}

As pointed out by Łasak (2008) the estimation procedure of the FVECM is further complicated with respect to the standard VECM (where $d$ and $b$ are restricted to be equal to 1 ), since the unknown parameters $d$ and $b$ need to be estimated. A solution to this problem, under the assumption $d=1$, is provided by Lasak (2008) that suggests to concentrate the likelihood function with 
TABLE IV

Model Selection Criteria for Different Lag Values $p$

\begin{tabular}{ccccccc}
\hline$p$ & 0 & 1 & 2 & 3 & 4 & 5 \\
\hline$H Q$ & -5.3208 & $-5.3496^{*}$ & -5.3492 & -5.3442 & -5.3459 & -5.3428 \\
$B I C$ & -5.3208 & $-5.3436^{*}$ & -5.3371 & -5.3261 & -5.3217 & -5.3126
\end{tabular}

Note. $H Q$ is the Hannan and Quinn information criterion, see Hannan and Quinn (1979). BIC is the Bayesian (Schwarz) information criterion, see Schwarz (1978).

respect to $b$. In this case, the model in (13) is estimated via a likelihood-based method analogous to that developed by Johansen (1991) for the standard VECM, where the initial step consists of maximizing the profile likelihood with respect to $b$. More recently, Johansen and Nielsen $(2010,2011)$ developed a joint estimation procedure for $d$ and $b$, that is also based on a profile likelihood method, but, differently from Lasak (2008), $d$ is not restricted to be 1 . The likelihood function is supposed to be Gaussian even though the true distribution of the error is not normal. Thus, we are in quasi-maximum likelihood framework. Johansen and Nielsen (2011) prove the existence and consistency of the maximum likelihood estimator (MLE) when $0<b \leq d$. When $b<1 / 2$, i.e. there is weak fractional cointegration using the terminology of Hualde and Robinson (2010), Johansen and Nielsen (2011) show that the asymptotic distribution of the ML estimates of model parameters is Gaussian. Appendix A reports the results of a Monte Carlo simulation that shows the finite-sample performances of the MLE in the case of weak fractional cointegration. The simulation confirms the asymptotic results of Johansen and Nielsen (2011), which is the convergence rate of the MLE of $\beta$ depends only on true value of $b$.

Since the number of lags included plays an important role in this context, we first implement two information-based criteria for the model selection. The Hannan and Quinn and Schwarz information criteria, in Table IV, are both minimized for $p=1$, so that we estimate the following model:

$$
\begin{aligned}
{\left[\begin{array}{ll}
\Delta^{d} & \log \sigma_{t, F} \\
\Delta^{d} & \log \sigma_{t, S}
\end{array}\right]=} & {\left[\begin{array}{cc}
\Delta^{d-b}-\Delta^{d} & 0 \\
0 & \Delta^{d-b}-\Delta^{d}
\end{array}\right]\left[\begin{array}{l}
\alpha_{1} \\
\alpha_{2}
\end{array}\right]\left[\begin{array}{ll}
1 & \beta
\end{array}\right]\left[\begin{array}{l}
\log \sigma_{t, F} \\
\log \sigma_{t, S}
\end{array}\right] } \\
& +\left[\begin{array}{ll}
\gamma_{11} & \gamma_{12} \\
\gamma_{21} & \gamma_{22}
\end{array}\right]\left[\begin{array}{cc}
1-\Delta^{b} & 0 \\
0 & 1-\Delta^{b}
\end{array}\right]\left[\begin{array}{ll}
\Delta^{d} & \log \sigma_{t, F} \\
\Delta^{d} & \log \sigma_{t, S}
\end{array}\right]+\left[\begin{array}{l}
\varepsilon_{t, F} \\
\varepsilon_{t, S}
\end{array}\right] .
\end{aligned}
$$

The results of the ML estimation procedure, with the asymptotic standard errors and the bootstrapped confidence intervals, are reported in Table V. The bootstrapped distribution has been generated with 1,000 replications obtained with wild bootstrap, that is robust to possible heteroskedastic and autocorrelated error terms, see Davidson (2002) and Cavaliere, Rahbek, and Taylor (2009). 
TABLE V

Estimation Results

\begin{tabular}{lcccc}
\hline & Estimate & $S E$ & $t$ & Bootstrap CI \\
\hline$d$ & 0.4737 & 0.0287 & 6.459 & $(0.4344,0.5375)$ \\
$b$ & 0.4737 & 0.0733 & 16.512 & $(0.2961,0.5721)$ \\
$\beta$ & -1.0009 & 0.0205 & -48.807 & $(-1.0449,-0.9570)$ \\
$\alpha_{1}$ & -0.2265 & 0.1738 & -1.303 & $(-0.5106,0.0505)$ \\
$\alpha_{2}$ & 0.6813 & 0.2776 & 2.454 & $(0.3756,0.9640)$ \\
$\gamma_{11}$ & -0.4769 & 0.1822 & -2.617 & $(-0.7639,-0.2034)$ \\
$\gamma_{12}$ & -0.2173 & 0.2334 & -1.113 & $(-0.4794,0.0734)$ \\
$\gamma_{21}$ & -0.2598 & 0.1742 & -1.248 & $(-0.5345,0.0389)$ \\
$\gamma_{22}$ & -0.5035 & 0.1686 & -2.987 & $0.7795,-0.2283)$ \\
$Q_{F}(5)$ & 0.879 & & $Q_{S}(5)$ & 0.583 \\
$Q_{F}(30)$ & 0.051 & & $Q_{S}(30)$ & 0.249 \\
$Q_{F}(50)$ & 0.061 & & $Q_{S}(50)$ & 0.787 \\
$J B_{F}$ & 0.210 & & $J B_{S}$ & 0.416 \\
$L M_{F}$ & 0.049 & & $L M_{S}$ & \\
\hline
\end{tabular}

Note. Table reports the estimated parameters of model in (14), the asymptotic standard errors (see Johansen and Nielsen, 2011), the $t$-statistic, and the $90 \%$ wild bootstrap confidence interval. Table also reports the $p$-values of Box-Pierce test $\left(Q_{F}\right.$ and $\left.Q_{S}\right)$ for lags 5,30 , and 50; the $p$-values of Jarque-Bera test of normality for spot and futures log-ranges $\left(J B_{F}\right.$ and $\left.J B_{S}\right)$, and the $P$-values of univariate $\mathrm{ARCH}$ tests with 5 lags $\left(L M_{F}\right.$ and $\left.L M_{S}\right)$.

The Monte Carlo results reported in Appendix A show that for a sample size larger than 2,000 observations and $d=b$, the finite-sample distribution of the ML estimates are very close to the limiting Gaussian distribution. The univariate analysis of the FVECM residuals indicates that the Gaussian assumption cannot be rejected by the standard Jarque-Bera test, even though we observe an ARCH effect in the futures log-range residuals. The Box-Pierce test signals a surviving autocorrelation in the residuals of the futures log-range equation. The value implied by the no-arbitrage condition, i.e. $\beta=-1$, is contained in the $90 \%$ confidence interval. This confirms the role of the no-arbitrage condition on the joint dynamics of the futures and the spot log-range, suggesting a one-to-one co-movement in the long run. Moreover, the estimates of $d$ and $b$ are close to the values obtained in the semi-parametric analysis in Section 2 . In particular, the fractional and cofractional integration orders are equal, $\hat{d}=\hat{b}$, so that a common stochastic trend, with long memory, is responsible for the long-run dependence of spot and futures log-ranges. From a visual inspection of Figure 2, it clearly appears that the ECM, $\log \sigma_{t, F}+\hat{\beta} \log \sigma_{t, S}$, does not have any residual long-memory component, as confirmed by the exact local Whittle estimate which is equal to 0.0007 .

It is also interesting to note that, during the financial crisis in 2001-2002, the long-run relationship is subject to a higher variability which can be caused by an increase in the uncertainty after September 11, 2001. 


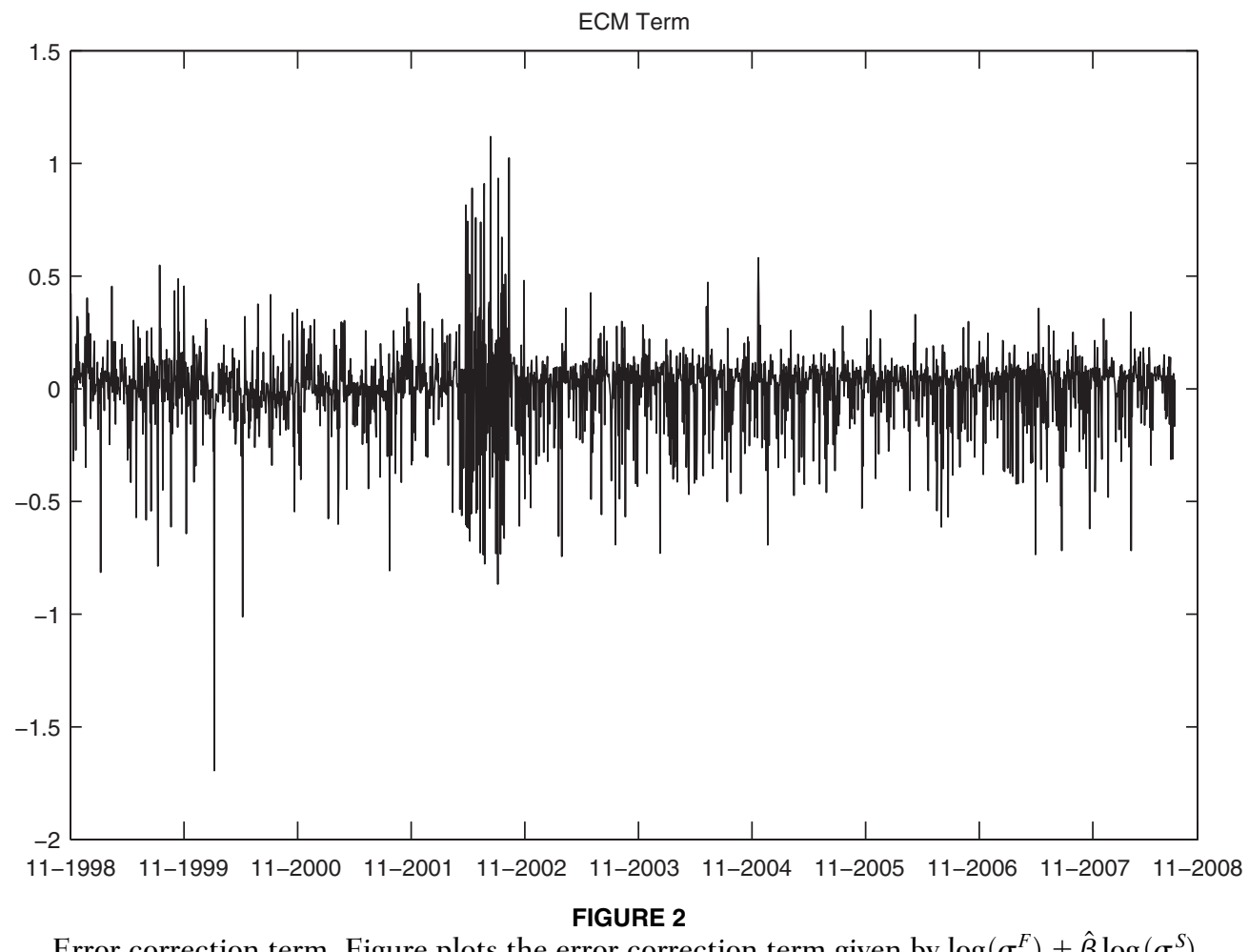

Error correction term. Figure plots the error correction term given by $\log \left(\sigma_{t}^{F}\right)+\hat{\beta} \log \left(\sigma_{t}^{S}\right)$.

An interesting feature that emerges from the estimates is that the spot logrange converges faster futures to than the equilibrium, since $\hat{\alpha}_{2}$ is greater than $\hat{\alpha}_{1}$ in absolute value. Moreover, $\alpha_{1}$ cannot be considered as statistically different from zero. Concluding, there are no changes in the futures log-range caused by shocks in the cointegration relation. All the corrections to the equilibrium are made by adjustments in the spot log-ranges. This means that futures volatility leads spot volatility to the equilibrium, implicitly confirming the Cox (1976)'s hypothesis on the efficiency of the futures market in processing the new information. In fact, according to the expectation hypothesis, the futures price, under risk neutrality, is the expected value of the future spot price, so that it is reasonable to think of futures log-ranges as the leading factor of the entire system.

\section{FORECASTS}

In order to evaluate the accuracy of the out-of-sample forecasts obtained with the FVECM, these are compared with the forecasts provided by alternative model specifications. In particular, six competing models are considered 
- Random walk model $(R W)$.

- Vector Autoregression model with 4 lags $(V A R) .{ }^{11}$

- Univariate HAR model (UHAR) proposed by Corsi (2009), where the observed log-range, for spot and futures, is regressed on its own daily, weekly, and monthly past values

$\log \sigma_{t, i}=\omega+\beta_{1} \log \sigma_{t-1, i}+\beta_{2} W_{t-1, i}+\beta_{3} M_{t-1, i}+u_{t}, \quad i=F, S$

where $W_{t-1, i}=\frac{1}{5} \sum_{j=1}^{5} \log \sigma_{t-j, i}$ and $M_{t-1, i}=\frac{1}{22} \sum_{j=1}^{22} \log \sigma_{t-j, i}$.

- Bivariate HAR (BHAR) where past values of the futures (spot) log-range are included in the equation of the spot (futures) log-range:

$$
\begin{aligned}
\log \sigma_{t, F}= & \omega_{1}+\beta_{11} \log \sigma_{t-1, F}+\beta_{12} W_{t-1, F}+\beta_{13} M_{t-1, F}+\beta_{14} \log \sigma_{t-1, S} \\
& +\beta_{15} W_{t-1, S}+\beta_{16} M_{t-1, S}+u_{t, F} \\
\log \sigma_{t, S}= & \omega_{2}+\beta_{21} \sigma_{t-1, F}+\beta_{22} W_{t-1, F}+\beta_{23} M_{t-1, F}+\beta_{24} \log \sigma_{t-1, S} \\
& +\beta_{25} W_{t-1, S}+\beta_{26} M_{t-1, S}+u_{t, S} .
\end{aligned}
$$

The system's parameters are estimated by least squares.

- Fractional Filter model $(F F)$ that accounts for the long memory in the data

$$
\Delta_{i}^{d} \log \sigma_{t, i}=u_{t}, \quad i=F, S
$$

where $u_{t} \sim$ i.i.d $N\left(0, v^{2}\right)$.

- $\operatorname{FiVAR}(1, \mathrm{~d})$ model $(F I V A R)$ :

$$
\left(\left[\begin{array}{ll}
1 & 0 \\
0 & 1
\end{array}\right]-\left[\begin{array}{ll}
\phi_{11} & \phi_{12} \\
\phi_{21} & \phi_{22}
\end{array}\right]\right)\left[\begin{array}{cc}
\Delta^{d_{F}} & 0 \\
0 & \Delta^{d_{S}}
\end{array}\right]\left[\begin{array}{c}
\log \sigma_{t, F} \\
\log \sigma_{t, S}
\end{array}\right]=\left[\begin{array}{l}
u_{t, F} \\
u_{t, S}
\end{array}\right] .
$$

The $\operatorname{FIVAR}(1, \mathrm{~d})$ can be considered a $\operatorname{VAR}(1)$ calculated on the fractionally differenced series.

The forecasts are based on parameter estimates from rolling samples with a fixed sample size of 1,350 days. For every date $t \geq 1,350$, the parameters of each specification are estimated with 1,350 observations including date $t$. Then, we calculate the forecasts of the average futures and spot log-ranges over the periods $t+1, \ldots, t+s$, where $s$ is equal to 1,5 , and 22, for daily, weekly, and monthly horizons, respectively. The presence of overlapping observations is avoided, meaning that we have 50 monthly, 220 weekly, and 1,100 daily forecasts. In this way, both short-term and long-term forecasts are considered

\footnotetext{
${ }^{11}$ The number of lags is chosen according to the Schwartz information criterion.
} 
TABLE VI

Forecasts Results

\begin{tabular}{|c|c|c|c|c|c|c|c|c|c|}
\hline \multirow[b]{2}{*}{$s$} & \multicolumn{3}{|c|}{ MSE } & \multicolumn{3}{|c|}{ RMSE } & \multicolumn{3}{|c|}{ MAE } \\
\hline & 1 & 5 & 22 & 1 & 5 & 22 & 1 & 5 & 22 \\
\hline \multicolumn{10}{|c|}{ (a) Futures } \\
\hline$R W$ & 0.271 & 0.068 & 0.070 & 0.521 & 0.261 & 0.295 & 0.421 & 0.204 & 0.236 \\
\hline$V A R$ & 0.178 & 0.067 & 0.078 & 0.423 & 0.260 & 0.279 & 0.341 & 0.206 & 0.213 \\
\hline$U H A R$ & 0.174 & 0.065 & 0.059 & 0.418 & 0.254 & 0.244 & 0.339 & 0.201 & 0.183 \\
\hline BHAR & 0.176 & 0.065 & 0.060 & 0.419 & 0.255 & 0.245 & 0.340 & 0.202 & 0.183 \\
\hline$F F$ & 0.187 & 0.068 & 0.069 & 0.432 & 0.261 & 0.262 & 0.350 & 0.211 & 0.199 \\
\hline FIVAR & 0.187 & 0.068 & 0.069 & 0.433 & 0.260 & 0.263 & 0.350 & 0.210 & 0.200 \\
\hline FVECM & 0.174 & 0.045 & 0.013 & 0.417 & 0.211 & 0.113 & 0.338 & 0.167 & 0.086 \\
\hline \multicolumn{10}{|l|}{ (b) Spot } \\
\hline$R W$ & 0.307 & 0.083 & 0.066 & 0.554 & 0.288 & 0.257 & 0.450 & 0.231 & 0.199 \\
\hline$V A R$ & 0.184 & 0.085 & 0.057 & 0.429 & 0.291 & 0.238 & 0.345 & 0.226 & 0.188 \\
\hline UHAR & 0.182 & 0.061 & 0.056 & 0.426 & 0.247 & 0.237 & 0.344 & 0.198 & 0.175 \\
\hline$B H A R$ & 0.181 & 0.062 & 0.054 & 0.425 & 0.248 & 0.233 & 0.344 & 0.199 & 0.175 \\
\hline$F F$ & 0.209 & 0.068 & 0.069 & 0.457 & 0.261 & 0.262 & 0.369 & 0.208 & 0.204 \\
\hline FIVAR & 0.204 & 0.068 & 0.068 & 0.452 & 0.261 & 0.261 & 0.365 & 0.207 & 0.204 \\
\hline FVECM & 0.186 & 0.044 & 0.013 & 0.430 & 0.210 & 0.112 & 0.348 & 0.160 & 0.084 \\
\hline
\end{tabular}

Note. Forecasts of average futures (Panel (a)) and spot (Panel (b)) log-ranges for different time horizons $(s=\{1,5,22\})$. Table reports the MSE, the RMSE, and the MAE of alternative models. In each column, figures in bold represent the minima.

(for an analogous analysis see Brandt and Jones, 2006). The actual average is defined as

$$
\bar{V}_{t+1, t+s}^{i}=\frac{1}{s} \sum_{\tau=1}^{s} \log \sigma_{t+\tau, i}, \quad i=F, S, \quad s=\{1,5,22\}
$$

The MSE, the RMSE, and the MAE statistics in Table VI clearly depict a situation where, except for daily forecasts of spot log-range, the FVECM outperforms the alternative models. It is particularly important to stress the fact that, considering longer forecasting horizons, the superior performance of the FVECM is more evident, for all statistics considered. The unbiasedness of the estimates is evaluated by regressing the actual average log-ranges on a constant and the corresponding out-of-sample forecast. This is the so-called Mincer and Zarnowitz (1969) regression which takes the following form:

$$
\bar{V}_{t+1, t+s}^{i}=\alpha+\beta \hat{V}_{t+1, t+s}^{i}+u_{t+1, t+s}, \quad i=F, S
$$

where $\hat{V}_{t+1, t+s}^{i}$ is the average of forecasts over the period $[t+1, t+s]$ for each model. Table VII reports the results of the Mincer-Zarnowitz regressions. In Panel $7(\mathrm{a})$, the regression adjusted $R^{2}$ 's for the FVECM turn out to be higher for all horizon considered with the exception of 1-day ahead for spot log-range. 
TABLE VII

Mincer-Zarnowitz Regression Results

\begin{tabular}{|c|c|c|c|c|c|c|}
\hline \multirow[b]{2}{*}{$s$} & \multicolumn{3}{|c|}{$\log \sigma_{t, F}$} & \multicolumn{3}{|c|}{$\log \sigma_{t, S}$} \\
\hline & 1 & 5 & 22 & 1 & 5 & 22 \\
\hline \multicolumn{7}{|c|}{ (a) Adjusted to $R^{2}$} \\
\hline$R W$ & 0.2178 & 0.4696 & 0.4406 & 0.1763 & 0.4986 & 0.4566 \\
\hline $\operatorname{VAR}(4)$ & 0.3013 & 0.5233 & 0.3312 & 0.3133 & 0.5596 & 0.3850 \\
\hline UHAR & 0.3155 & 0.5391 & 0.4575 & 0.3186 & 0.5691 & 0.5047 \\
\hline BVAR & 0.3120 & 0.5367 & 0.4353 & 0.3229 & 0.5750 & 0.5035 \\
\hline FF & 0.2974 & 0.5302 & 0.3909 & 0.2667 & 0.5404 & 0.4280 \\
\hline FIVAR & 0.2984 & 0.5316 & 0.3895 & 0.2761 & 0.5424 & 0.4247 \\
\hline FVECM & 0.3212 & 0.7389 & 0.8787 & 0.3182 & 0.7380 & 0.8868 \\
\hline \multicolumn{7}{|c|}{ (b) $H_{0}: \alpha=0$ vs $H_{1}: \alpha \neq 0$} \\
\hline$R W$ & $\begin{array}{c}-2.7637 \\
(-19.65)\end{array}$ & $\begin{array}{l}-1.6063 \\
(-6.028)\end{array}$ & $\begin{array}{l}-1.6896 \\
(-\mathbf{3 . 0 6 5 )}\end{array}$ & $\begin{array}{c}-3.002 \\
(-\mathbf{2 1 . 4 0})\end{array}$ & $\begin{array}{c}-1.5140 \\
(-6.008)\end{array}$ & $\begin{array}{c}-1.5404 \\
(-2.574)\end{array}$ \\
\hline $\operatorname{VAR}(4)$ & $\begin{array}{c}-0.3017 \\
(-1.315)\end{array}$ & $\begin{array}{c}-0.2520 \\
(0.3324)\end{array}$ & $\begin{array}{l}-1.8054 \\
(-2.960)\end{array}$ & $\begin{array}{c}-0.2885 \\
(1.301)\end{array}$ & $\begin{array}{l}-0.2370 \\
(-0.776)\end{array}$ & $\begin{array}{l}-1.6327 \\
(-2.898)\end{array}$ \\
\hline UHAR & $\begin{array}{l}-0.1517 \\
(-0.672)\end{array}$ & $\begin{array}{l}-0.2008 \\
(-0.604)\end{array}$ & $\begin{array}{c}-1.2324 \\
(-2.049)\end{array}$ & $\begin{array}{l}-0.1325 \\
(-0.528)\end{array}$ & $\begin{array}{l}-0.1649 \\
(-0.776)\end{array}$ & $\begin{array}{c}-1.0958 \\
(-1.981)\end{array}$ \\
\hline$B V A R$ & $\begin{array}{r}-0.2111 \\
(-0.935)\end{array}$ & $\begin{array}{l}-0.2234 \\
(-0.674)\end{array}$ & $\begin{array}{l}-1.3733 \\
(-2.291)\end{array}$ & $\begin{array}{c}-0.2483 \\
(1.144)\end{array}$ & $\begin{array}{l}-0.2639 \\
(-0.871)\end{array}$ & $\begin{array}{r}0.5226 \\
(-2.338)\end{array}$ \\
\hline$F F$ & $\begin{array}{c}-1.300 \\
(-7.453)\end{array}$ & $\begin{array}{c}-0.6913 \\
(-\mathbf{2 . 2 8 7})\end{array}$ & $\begin{array}{l}-1.5134 \\
(-2.514)\end{array}$ & $\begin{array}{c}-1.535 \\
(-8.816)\end{array}$ & $\begin{array}{c}-0.8024 \\
(-2.782)\end{array}$ & $\begin{array}{c}-1.4613 \\
(-2.554)\end{array}$ \\
\hline FIVAR & $\begin{array}{c}-1.297 \\
(-8.053)\end{array}$ & $\begin{array}{c}-0.6978 \\
(-2.281)\end{array}$ & $\begin{array}{l}-1.5221 \\
(-2.545)\end{array}$ & $\begin{array}{c}-1.415 \\
(-8.053)\end{array}$ & $\begin{array}{c}-0.8009 \\
(-2.788)\end{array}$ & $\begin{array}{r}-1.4656 \\
(-2 . .583)\end{array}$ \\
\hline FVECM & $\begin{array}{c}-0.2283 \\
(-1.044)\end{array}$ & $\begin{array}{c}0.5157 \\
(\mathbf{2} .061)\end{array}$ & $\begin{array}{c}0.5621 \\
(1.585)\end{array}$ & $\begin{array}{l}-0.5117 \\
(-2.469)\end{array}$ & $\begin{array}{c}0.2998 \\
(1.295)\end{array}$ & $\begin{array}{c}0.4512 \\
(1.5453)\end{array}$ \\
\hline \multicolumn{7}{|c|}{ (c) $H_{0}: \beta=1$ vs $H_{1}: \beta \neq 1$} \\
\hline RW & $\begin{array}{c}0.4671 \\
(\mathbf{1 7 . 3 1})\end{array}$ & $\begin{array}{c}0.6895 \\
(13.50)\end{array}$ & $\begin{array}{c}0.6731 \\
(\mathbf{2} .342)\end{array}$ & $\begin{array}{c}0.4204 \\
(\mathbf{1 5 . 8 4})\end{array}$ & $\begin{array}{c}0.7072 \\
(\mathbf{1 4 . 6 2 )}\end{array}$ & $\begin{array}{c}0.7015 \\
(6.207)\end{array}$ \\
\hline $\operatorname{VAR}(4)$ & $\begin{array}{r}0.9421 \\
(1.307)\end{array}$ & $\begin{array}{r}0.9511 \\
(0.767)\end{array}$ & $\begin{array}{r}0.7341 \\
(\mathbf{2 . 3 4 2})\end{array}$ & $\begin{array}{c}0.9445 \\
(1.291)\end{array}$ & $\begin{array}{c}0.9538 \\
(0.874)\end{array}$ & $\begin{array}{c}0.6819 \\
(\mathbf{2 . 9 8 1 )}\end{array}$ \\
\hline UHAR & $\begin{array}{c}0.9705 \\
(0.678)\end{array}$ & $\begin{array}{c}0.9612 \\
(0.610)\end{array}$ & $\begin{array}{c}0.7616 \\
(\mathbf{2 . 0 9 5 )}\end{array}$ & $\begin{array}{c}0.9741 \\
(0.594)\end{array}$ & $\begin{array}{c}0.9680 \\
(0.534)\end{array}$ & $\begin{array}{c}0.7873 \\
(\mathbf{2 . 0 3 4})\end{array}$ \\
\hline$B V A R$ & $\begin{array}{c}0.9593 \\
(0.934)\end{array}$ & $\begin{array}{c}0.9571 \\
(0.675)\end{array}$ & $\begin{array}{r}0.7341 \\
(\mathbf{2 . 3 4 2})\end{array}$ & $\begin{array}{c}0.9519 \\
(1.146)\end{array}$ & $\begin{array}{c}0.9492 \\
(0.786)\end{array}$ & $\begin{array}{c}0.7627 \\
(\mathbf{2 . 3 9 7})\end{array}$ \\
\hline$F F$ & $\begin{array}{c}0.7482 \\
(7.508)\end{array}$ & $\begin{array}{c}0.8655 \\
(\mathbf{2 . 2 9 0})\end{array}$ & $\begin{array}{c}0.7055 \\
(\mathbf{2} .575)\end{array}$ & $\begin{array}{c}0.7024 \\
(\mathbf{8 . 8 8 8})\end{array}$ & $\begin{array}{c}0.8439 \\
(\mathbf{2 . 8 3 1})\end{array}$ & $\begin{array}{c}0.7156 \\
(\mathbf{2 . 6 1 4})\end{array}$ \\
\hline FIVAR & $\begin{array}{c}0.7487 \\
(7.524)\end{array}$ & $\begin{array}{c}0.8644 \\
(2.316)\end{array}$ & $\begin{array}{c}0.7038 \\
(\mathbf{2} .606)\end{array}$ & $\begin{array}{c}0.7256 \\
(\mathbf{8 . 1 0 9})\end{array}$ & $\begin{array}{c}0.8444 \\
(2.831)\end{array}$ & $\begin{array}{c}0.7147 \\
(2.646)\end{array}$ \\
\hline FVECM & $\begin{array}{c}0.9550 \\
(0.2868)\end{array}$ & $\begin{array}{c}1.0995 \\
(4.2859)\end{array}$ & $\begin{array}{l}1.1074 \\
(2.545)\end{array}$ & $\begin{array}{c}0.8999 \\
(6.222)\end{array}$ & $\begin{array}{c}1.0577 \\
(0.1968)\end{array}$ & $\begin{array}{c}1.0859 \\
(1.5437)\end{array}$ \\
\hline \multicolumn{7}{|c|}{ (d) $H_{0}: \alpha=0 \cap \beta=1$ vs $H_{1}: \alpha \neq 0 \cap \beta \neq 1$} \\
\hline RW & $\begin{array}{l}194.90 \\
(\mathbf{0 . 0 0 0 0})\end{array}$ & $\begin{array}{l}18.628 \\
(0.0000)\end{array}$ & $\begin{array}{c}5.5173 \\
(\mathbf{0 . 0 0 6 9 )}\end{array}$ & $\begin{array}{l}243.63 \\
(0.0000)\end{array}$ & $\begin{array}{l}18.391 \\
(\mathbf{0 . 0 0 0 0 )}\end{array}$ & $\begin{array}{c}4.1269 \\
(\mathbf{0 . 0 2 2 3})\end{array}$ \\
\hline $\operatorname{VAR}(4)$ & $\begin{array}{c}0.8713 \\
(0.4186)\end{array}$ & $\begin{array}{c}0.3056 \\
(0.7369)\end{array}$ & $\begin{array}{c}5.3746 \\
(\mathbf{0 . 0 0 7 8})\end{array}$ & $\begin{array}{c}0.8553 \\
(0.4254)\end{array}$ & $\begin{array}{c}0.3204 \\
(0.7261)\end{array}$ & $\begin{array}{c}5.1663 \\
(\mathbf{0 . 0 0 9 3})\end{array}$ \\
\hline UHAR & $\begin{array}{c}0.2332 \\
(0.7920)\end{array}$ & $\begin{array}{c}0.1909 \\
(0.8263)\end{array}$ & $\begin{array}{c}2.5324 \\
(\mathbf{0 . 0 9 0 0 )}\end{array}$ & $\begin{array}{r}0.18114 \\
(0.8343)\end{array}$ & $\begin{array}{c}0.1489 \\
(0.8617)\end{array}$ & $\begin{array}{c}2.4580 \\
(\mathbf{0 . 0 9 6 3 )}\end{array}$ \\
\hline$B V A R$ & $\begin{array}{c}0.4368 \\
(0.6461)\end{array}$ & $\begin{array}{c}0.2283 \\
(0.7960)\end{array}$ & $\begin{array}{c}2.50294 \\
(\mathbf{0 . 0 9 2 4})\end{array}$ & $\begin{array}{c}0.6570 \\
(0.5185)\end{array}$ & $\begin{array}{c}0.3823 \\
(0.6827)\end{array}$ & $\begin{array}{c}0.6480 \\
(\mathbf{0 . 0 8 1 1})\end{array}$ \\
\hline$F F$ & $\begin{array}{l}28.298 \\
(0.0000)\end{array}$ & $\begin{array}{c}2.8167 \\
(\mathbf{0 . 0 6 2 1})\end{array}$ & $\begin{array}{c}3.7847 \\
(\mathbf{0 . 0 2 9 8})\end{array}$ & $\begin{array}{r}0.85531 \\
(0.4254)\end{array}$ & $\begin{array}{c}4.2786 \\
(0.0150)\end{array}$ & $\begin{array}{c}3.842 \\
(0.0283)\end{array}$ \\
\hline FIVAR & $\begin{array}{l}28.400 \\
(0.0000)\end{array}$ & $\begin{array}{c}2.8412 \\
(0.0605)\end{array}$ & $\begin{array}{l}3.86473 \\
(\mathbf{0 . 0 2 7 8})\end{array}$ & $\begin{array}{l}32.976 \\
(0.000)\end{array}$ & $\begin{array}{c}4.8149 \\
(\mathbf{0 . 0 0 8 9})\end{array}$ & $\begin{array}{c}3.9590 \\
(\mathbf{0 . 0 2 5 6})\end{array}$ \\
\hline FVECM & $\begin{array}{c}0.6284 \\
(0.5336)\end{array}$ & $\begin{array}{c}2.1518 \\
(0.1187)\end{array}$ & $\begin{array}{c}1.2900 \\
(0.2848)\end{array}$ & $\begin{array}{l}3.164 \\
(\mathbf{0 . 0 4 2 6})\end{array}$ & $\begin{array}{c}0.8386 \\
(0.433)\end{array}$ & $\begin{array}{c}0.7727 \\
(0.4675)\end{array}$ \\
\hline
\end{tabular}

Panel 7(a) reports the Mincer-Zarnowitz regression adjusted $R^{2}$, in bold the highest $R^{2}$ among the models considered for each forecast horizon. Panel 7(b) and (c) report estimates of the intercept and slope coefficients, $\alpha$ and $\beta$, in the regression (16). The $t$-statistics, in parenthesis, are computed using Newey-West standard errors. In bold when the null hypothesis $(\alpha=0$ or $\beta=1)$ is rejected at $5 \%$ significance level. Panel 7(d) reports the $F$ test statistic for the joint hypothesis $\alpha=0 \cap \beta=1$, the $P$-values are in parenthesis, in bold when the null hypothesis is rejected at $10 \%$ significance level. 
The fit is particularly good for longer horizons. The Mincer-Zarnowitz coefficient estimates are presented in Panel 7(b) and 7(c), respectively. The test statistic for the restriction that $\alpha=0$ and $\beta=1$ is reported in Panel 7(d).

It clearly emerges that the FVECM, differently from alternative specifications, provides unbiased forecasts for all different choices of $s$, with the exception of the spot ranges when $s=1$. It is noteworthy that when $s=22$ the FVECM strongly overperforms the competing models. When considering longer forecast horizons, the fractional cointegration restriction improves the forecasts of spot log-ranges, since the adjustment mechanism implicit in the FVECM operates to restore the equilibrium. A test for the forecasting superiority of FVECM is carried out in Diebold and Mariano (1995) framework, focusing here on the mean squared error (MSE), see Patton (2011) for the choice of the loss function. The forecasting error of model $i$ at date $t$ is defined as the difference, $\varepsilon_{i, t}$, between the sample average of the log-ranges in the period $[t+1, t+s]$ and the corresponding forecast provided by model $i$ :

$\varepsilon_{i, n}=\bar{V}_{t+1, t+s}^{i}-\hat{V}_{t+1, t+s}^{i} s=\{1,5,22\}, n=1, \ldots, N, t=1350, \ldots, T-s$

where $N=(T-1,350) / s$ represents the number of forecasts, and is equal to $1,100,220,50$ for the daily, weekly, and monthly horizon, respectively. Specifically, the interest is on the measure of the relative forecasting performance of the different model specifications, testing the superiority of model $i$ over FVECM, which is the benchmark, with a $t$-test for the null hypothesis that $\mu_{i}=0$ in

$$
\varepsilon_{i, n}^{2}-\varepsilon_{F V E C M, n}^{2}=\mu_{i}+\nu_{n}, \quad i=F, S
$$

where a positive estimate of $\mu_{i}$ indicates support for the FVECM. Table VIII reports the $t$-statistics for the estimates of $\mu_{i}$, for all choices of $s$, and it clearly depicts a situation where the forecast errors associated with FVECM are significantly smaller than those of the competing models, in particular for longer horizons. Moreover, the values of the $t$-tests are positive and significant in most cases, that is the FVECM forecasts are more accurate than those of alternative models considered. In particular, the forecasting ability of FVECM can be attributed to its equilibrium adjustment mechanism, that in this case systematically leads to superior forecasting performances. Indeed, the FVECM dominates the alternative multivariate models considered, e.g. BHAR and FIVAR, which differ from the FVECM for the absence of an error correction term. It is interesting to note the superiority of FVECM's forecasts of the spot log-range at weekly and monthly horizons. This is due to the error correction mechanism that induces the convergence of spot log-range to the long-run equilibrium. These results suggest that properly accounting for the long-run relation 
TABLE VIII

Diebold-Mariano Test

\begin{tabular}{|c|c|c|c|c|c|c|}
\hline \multirow[b]{2}{*}{$s$} & \multicolumn{3}{|c|}{$\log \sigma_{t, F}$} & \multicolumn{3}{|c|}{$\log \sigma_{t, S}$} \\
\hline & 1 & 5 & 22 & 1 & 5 & 22 \\
\hline$R W$ & $8.914^{a}$ & $6.143^{\mathrm{a}}$ & $3.805^{a}$ & $6.411^{\mathrm{a}}$ & $9.769^{\mathrm{a}}$ & $3.235^{\mathrm{a}}$ \\
\hline $\operatorname{VAR}(4)$ & $1.715^{\mathrm{c}}$ & $7.151^{\mathrm{a}}$ & $3.583^{a}$ & 0.288 & $5.871^{a}$ & $3.715^{\mathrm{a}}$ \\
\hline UHAR & 0.534 & $8.153^{\mathrm{a}}$ & $3.405^{\mathrm{a}}$ & -0.352 & $7.055^{\mathrm{a}}$ & $3.401^{\mathrm{a}}$ \\
\hline$B H A R$ & 0.900 & $8.368^{\mathrm{a}}$ & $3.664^{a}$ & -0.627 & $6.952^{\mathrm{a}}$ & $3.611^{\mathrm{a}}$ \\
\hline$F F$ & $3.277^{\mathrm{a}}$ & $7.792^{\mathrm{a}}$ & $3.382^{\mathrm{a}}$ & $4.210^{\mathrm{a}}$ & $6.640^{\mathrm{a}}$ & $3.611^{\mathrm{a}}$ \\
\hline FIVAR & $3.246^{a}$ & $7.760^{\mathrm{a}}$ & $3.980^{\mathrm{a}}$ & $3.674^{\mathrm{a}}$ & $6.543^{\mathrm{a}}$ & $3.613^{\mathrm{a}}$ \\
\hline
\end{tabular}

Note. Table reports the $t$-statistic of the estimate of $\mu_{t}$ in the regression $\varepsilon_{i, n}^{2}-\varepsilon_{F V E C M, n}^{2}=\mu_{i}+\eta_{n}$, where $\varepsilon_{i, n}$ is the forecast error of model $i$ in period $t$ for a given forecast horizon s. $a, b$ and $c$ denote 1, 5, and $10 \%$ significance level of the corresponding $t$-ratio test.

between log-ranges, that is implicit in the no-arbitrage pricing, provides a significant forecast improvement, since the futures log-range, given the speculative nature of futures contracts, leads the spot log-range.

Finally, the log-range forecasts can be employed to obtain estimates of the Value-at-Risk ( $\mathrm{VaR}$ ) for both assets. We compute for each asset the daily and weekly VaR at $5 \%$ level. The quantile used in the computation is obtained fitting a Student's density to the returns data. The weekly VaR for each model is calculated with $\sqrt{5} \cdot \exp \left\{\hat{V}_{t+1, t+5}^{i}+\frac{1}{2} \hat{\omega}_{i}^{2}\right\}, i=F, S$, where $\hat{\omega}_{i}^{2}$ denotes the estimate of the forecast error variance.

The results of the VaR analysis, for the daily and the weekly horizons, are reported in Table IX. ${ }^{12}$ The table reports the number of VaR exceedances at 5\% and the $P$-values of the Kupiec (1995) (KP) and Christoffersen (1998) (CH) tests for the null hypothesis that the observed frequency of $\mathrm{VaR}$ exceedances is not statically different from 5\%. In all cases, the observed probability that returns exceed the VaR threshold based on FVECM is not statistically different from the 5\%. This result generally holds for the other models too. In order to evaluate the economic value of the VaR forecasts, the following loss functions are also employed:

$$
\begin{aligned}
& L F_{1}=\frac{100}{J} \sum_{j=1}^{J}\left(r_{j}-V a R_{j}\right)^{2} \\
& L F_{2}=\frac{100}{J} \sum_{j=1}^{J}\left|r_{j}-V a R_{j}\right|
\end{aligned}
$$

where $J$ indicates the length of the forecast sample, that is $J=1,100$ for the daily $\mathrm{VaR}$ and $J=220$ for the weekly VaR. The rationale behind this choice for

\footnotetext{
${ }^{12}$ The sample of 50 monthly forecasts is too small to guarantee a reliable VaR exercise.
} 
TABLE IX

VaR Results

\begin{tabular}{|c|c|c|c|c|c|c|c|c|c|c|}
\hline & \multicolumn{5}{|c|}{ Futures } & \multicolumn{5}{|c|}{ Spot } \\
\hline & Exc & $K P$ & $\mathrm{CH}$ & $L F_{1}$ & $L F_{2}$ & Exc & $K P$ & $\mathrm{CH}$ & $L F_{1}$ & $L F_{2}$ \\
\hline \multicolumn{11}{|l|}{ Daily } \\
\hline$R W$ & 5.18 & 0.7832 & 0.3551 & 0.0356 & 1.5543 & 4.82 & 0.7808 & 0.0624 & 0.0364 & 1.5693 \\
\hline $\operatorname{VAR}(4)$ & 4.45 & 0.3981 & 0.0307 & 0.0273 & 1.4059 & 4.18 & 0.2006 & 0.3161 & 0.0282 & 1.4232 \\
\hline UHAR & 4.18 & 0.2006 & 0.0140 & 0.0272 & 1.4008 & 4.09 & 0.1537 & 0.0116 & 0.0280 & 1.4163 \\
\hline$B V A R$ & 4.09 & 0.1537 & 0.0116 & 0.0273 & 1.4035 & 3.91 & 0.0848 & 0.0075 & 0.0283 & 1.4204 \\
\hline$F F$ & 4.91 & 0.8897 & 0.4531 & 0.0292 & 1.4415 & 4.64 & 0.5755 & 0.4731 & 0.0303 & 1.4607 \\
\hline FIVAR & 4.82 & 0.7808 & 0.4703 & 0.0294 & 1.4429 & 4.45 & 0.3981 & 0.4333 & 0.0302 & 1.4587 \\
\hline FVECM & 4.64 & 0.5755 & 0.0235 & 0.0274 & 1.4030 & 5.00 & 1.0000 & 0.1444 & 0.0287 & 1.4277 \\
\hline \multicolumn{11}{|l|}{ Weekly } \\
\hline$R W$ & 2.73 & 0.0917 & 0.1980 & 0.0911 & 2.5558 & 1.36 & 0.0035 & 0.0135 & 0.1009 & 2.7186 \\
\hline $\operatorname{VAR}(4)$ & 5.91 & 0.5471 & 0.3453 & 0.0863 & 2.5003 & 4.09 & 0.5235 & 0.5320 & 0.0946 & 2.6510 \\
\hline UHAR & 6.36 & 0.3723 & 0.2416 & 0.0876 & 2.5118 & 3.64 & 0.3303 & 0.4429 & 0.0981 & 2.6726 \\
\hline$B V A R$ & 5.91 & 0.5471 & 0.3453 & 0.0879 & 2.5190 & 4.55 & 0.7535 & 0.5629 & 0.0969 & 2.6656 \\
\hline$F F$ & 5.91 & 0.5471 & 0.3453 & 0.0885 & 2.5134 & 3.64 & 0.3303 & 0.4429 & 0.0981 & 2.6726 \\
\hline FIVAR & 5.91 & 0.5471 & 0.3453 & 0.0887 & 2.5172 & 3.64 & 0.3303 & 0.4429 & 0.0983 & 2.6773 \\
\hline FVECM & 6.82 & 0.2398 & 0.1548 & 0.0862 & 2.4852 & 4.09 & 0.5235 & 0.5320 & 0.0944 & 2.6391 \\
\hline
\end{tabular}

Note. Table reports the percentage of VaR exceedances $(E x c)$ for each model, the $p$-value of the Kupiec, $K P$, and Christoffersen tests, $\mathrm{CH}$, respectively; $L F_{1}$ and $L F_{2}$ are the loss functions defined in (19).

the loss functions is that once the null hypotheses of $K P$ and $C H$ tests are not rejected a bank is clearly interested in minimizing the distance between the observed returns and the VaR. It is noteworthy the fact that, according to the loss functions, the VaR based on the fractional cointegration model provides the best performance at the weekly horizon for both futures and spot prices. At daily horizon, the loss functions are very close to those obtained with the UHAR. This evidence further corroborates the forecasting results, namely that the ECM, included in the FVECM, improves the precision of the long-run forecasts but is less effective in the short run.

\section{CONCLUSIONS}

This study presents an innovative model setup, based on a well-known no-arbitrage pricing formula, which exploits the efficient information contained in the futures log-range series, in order to provide superior forecasts of the spot logrange. Given the long-memory property of the log-range series, the analysis is carried out in terms of fractional cointegration so that the dynamic behavior of the two series is modeled by a fractional VECM model, as defined by Johansen (2008). The cointegrated system is estimated, by means of a profile likelihood 
technique, that allows to jointly estimate fractional and cofractional orders. This technique extends the estimation method proposed in Łasak (2008) and Johansen and Nielsen (2011). A clear empirical evidence confirms the presence of a common stochastic trend with long memory that captures the total persistence of the system, so that the error correction term is integrated of order 0 . Moreover, the parameter $\beta$ is close to the theoretical value -1 , and the spot log-range converges faster to the long-run equilibrium than the futures log-range. This evidence suggests that futures volatility, as measured by the range, is the driving factor in the volatility process, given that the futures contracts are more efficient in processing the new information. Allowing for the long-range dependence between spot and futures volatility improves significantly the out-of-sample forecasts, given the equilibrium mechanism that is incorporated in the model for fractional cointegration, and, as a by-product, provides more reliable VaR forecasts.

\section{APPENDIX A: SIMULATION STUDY}

The finite-sample properties of the profile ML procedure, outlined in Johansen and Nielsen (2011), are evaluated by means of a Monte Carlo simulation. Two stationary fractionally cointegrated processes are generated from an FVECM, without short-term dynamics

$$
\begin{aligned}
& Y_{t}=\alpha_{1}\left(\Delta^{-b}-1\right)\left(Y_{t}-\beta X_{t}\right)+\Delta^{-d} \varepsilon_{1 t} \\
& X_{t}=\alpha_{2}\left(\Delta^{-b}-1\right)\left(Y_{t}-\beta X_{t}\right)+\Delta^{-d} \varepsilon_{2 t}
\end{aligned}
$$

where $d=0.4, \beta=1$, and $\alpha=(-0.5,0.5)$. The parameter $b$ assumes values 0.4 and 0.3 . The infinite moving-average representation of the long-memory process, $\mu_{t}$, is given by

$$
u_{i, t}=\Delta^{-d} \varepsilon_{i, t}=\sum_{i=0}^{\infty} \psi_{i} \varepsilon_{i, t-i}
$$

where $v_{i}=i^{d-1} /(d-1)$ as $i \rightarrow \infty$, see Hosking (1981). From a practical point of view, a truncated version of (22) is considered, that is

$$
u_{i, t}^{+}=\sum_{i=0}^{t-1} \psi_{i} \varepsilon_{i, t-i}
$$

where the pre-sample values are assumed to be equal to zero.

The Monte Carlo experiment is based on 1,000 replications, with $T$ observations each, where $T=\{500,1,000,2,000\} . \varepsilon_{1 t}$ and $\varepsilon_{2 t}$ are randomly generated from a bivariate normal distribution with mean 0 , variance 1 , and correlation 
TABLE X

Monte Carlo Results

\begin{tabular}{|c|c|c|c|c|c|c|}
\hline \multirow[t]{2}{*}{$T$} & \multicolumn{2}{|c|}{2000} & \multicolumn{2}{|c|}{1000} & \multicolumn{2}{|c|}{500} \\
\hline & 0.3 & 0.4 & 0.3 & 0.4 & 0.3 & 0.4 \\
\hline$Q_{50, \hat{d}}$ & 0.4011 & 0.4015 & 0.4015 & 0.4029 & 0.4056 & 0.4014 \\
\hline$Q_{5, \hat{d}}$ & 0.3702 & 0.3697 & 0.3572 & 0.3570 & 0.3399 & 0.3435 \\
\hline$Q_{95, \hat{d}}$ & 0.4299 & 0.4306 & 0.4420 & 0.4404 & 0.4577 & 0.4583 \\
\hline$R M S E$ & 0.0178 & 0.0184 & 0.0261 & 0.0252 & 0.0361 & 0.0357 \\
\hline$Q_{50, \hat{b}}$ & 0.3072 & 0.4043 & 0.3076 & 0.4086 & 0.3244 & 0.4233 \\
\hline$Q_{5, \hat{b}}$ & 0.1860 & 0.3092 & 0.1297 & 0.2761 & 0.0507 & 0.2145 \\
\hline$Q_{95, \hat{b}}$ & 0.4268 & 0.5076 & 0.4771 & 0.5426 & 0.5920 & 0.6329 \\
\hline RMSE & 0.0733 & 0.0594 & 0.1087 & 0.0822 & 0.1695 & 0.1293 \\
\hline$Q_{50, \hat{\beta}}$ & -1.0000 & -1.0002 & -1.0005 & -0.9996 & -0.9978 & -0.9996 \\
\hline$Q_{5, \hat{\beta}}$ & -1.0215 & -1.0152 & -1.0388 & -1.0203 & -1.0530 & -1.0301 \\
\hline$Q_{95, \hat{\beta}}$ & -0.9772 & -0.9867 & -0.9681 & -0.9794 & -0.9490 & -0.9691 \\
\hline RMSE & 0.0134 & 0.0085 & 0.0206 & 0.0124 & 0.0311 & 0.0183 \\
\hline$Q_{50, \hat{\alpha}_{1}}$ & -0.4837 & -0.4908 & -0.4927 & -0.4894 & -0.4329 & -0.4600 \\
\hline$Q_{5, \hat{\alpha}_{1}}$ & -1.0273 & -0.8458 & -1.6025 & -1.1012 & -1.9003 & -1.4107 \\
\hline$Q_{95, \hat{\alpha}_{1}}$ & -0.1509 & -0.2085 & -0.0396 & -0.1284 & 0.3624 & 0.0388 \\
\hline$R M S E$ & 0.2567 & 0.1835 & 0.4801 & 0.2500 & 0.7043 & 0.4184 \\
\hline$Q_{50, \hat{\alpha}_{2}}$ & 0.5033 & 0.4868 & 0.4663 & 0.4894 & 0.4490 & 0.4698 \\
\hline$Q_{5, \hat{\alpha}_{2}}$ & 0.1408 & 0.2099 & -0.0710 & 0.1303 & -0.2989 & -0.0591 \\
\hline$Q_{95, \hat{\alpha}_{2}}$ & 1.0428 & 0.8339 & 1.4173 & 1.0015 & 1.9363 & 1.3114 \\
\hline RMSE & 0.2718 & 0.1814 & 0.4402 & 0.2485 & 0.7103 & 0.3953 \\
\hline
\end{tabular}

Note. Table reports the median $\left(Q_{50}\right)$, the 5 th $\left(Q_{5}\right)$ and 95 th $\left(Q_{95}\right)$ percentile of MLE $\hat{d}, \hat{b}, \hat{\beta}$, and $\hat{\alpha}$ for $T=2,000,1,000,500$ observations and 1,000 replications. In the simulations, $d=0.4, \alpha=(-0.5,0.5)$, and $\beta=-1$. The values of $b$ used in the Monte Carlo are reported.

equal to 0.9 (these values are close to those observed in the futures-spot data set). All the parameters are then estimated following the Johansen and Nielsen (2011) method, assuming that the cointegration rank is known and equal to 1 . The percentiles of the Monte Carlo distribution of the parameters estimates are reported in Table $X$. The precision in the estimation of the parameters increases with the sample size. This is due to the long-memory feature of the generated series. Moreover, the parameter dispersion, as measured by the $R M S E$, increases with the difference between $d$ and $b$, as already noted by Lasak (2008). Notably, the MLE of $\beta$ is fairly precise also for moderate sample sizes; see the plots in Figure 3. Moreover, the Monte Carlo distribution of $\hat{\beta}$ is clearly much more concentrated around the true value when $b=0.4$ with respect to the case of $b=0.3$. This is consistent with the results of Johansen and Nielsen (2011) that establish that the convergence rate of $\hat{\beta}$ is equal to $T^{b}$. On the other hand, the estimates of the vector $\alpha$ appear to be more dispersed; this is due to the fact that $\hat{\alpha}$ is a function of $\hat{d}, \hat{b}$, and $\hat{\beta}$, and hence it is affected by the estimation uncertainty present in the previous step. As shown in Figure 3, 
$\beta$

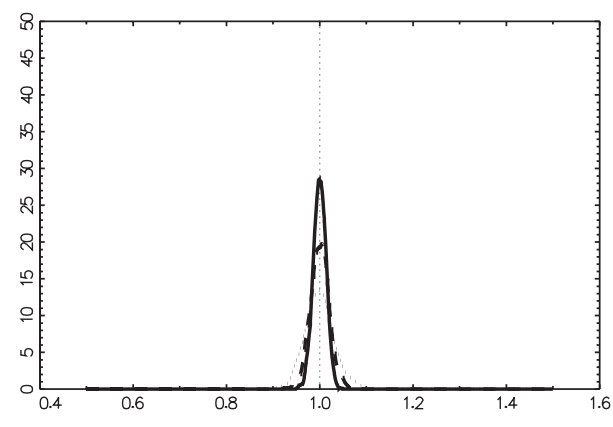

$\alpha_{2}$
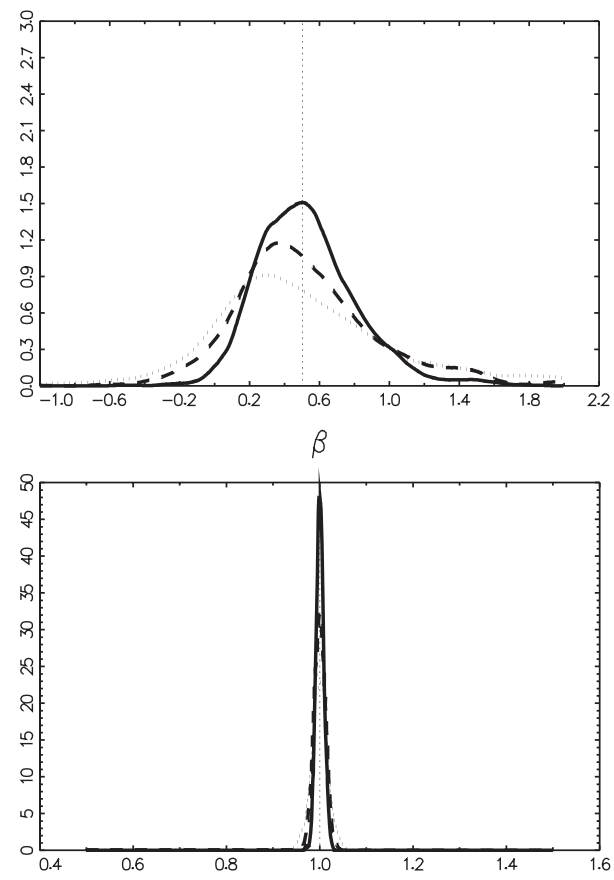

$\alpha_{2}$

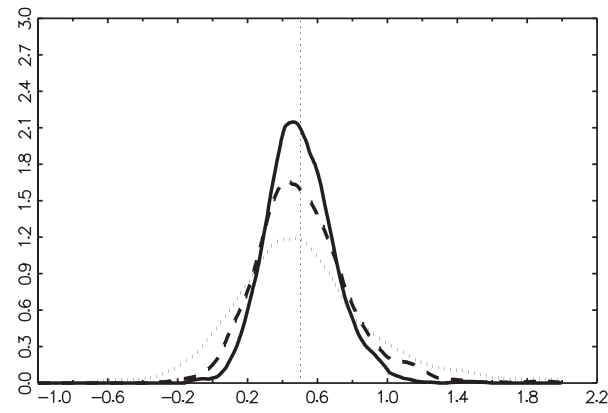

$\alpha_{1}$

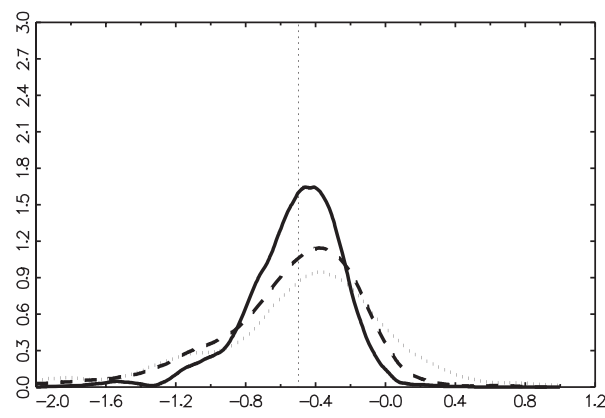

b
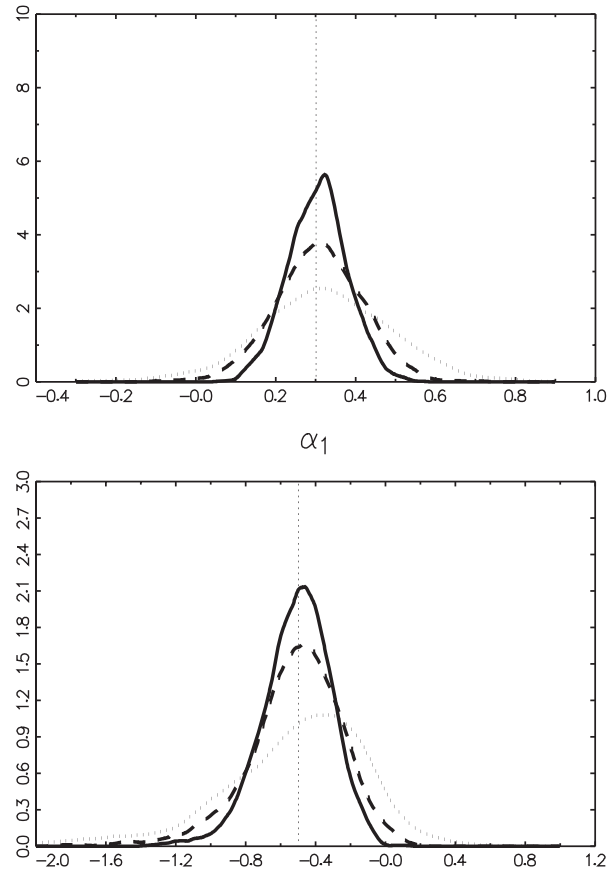

b

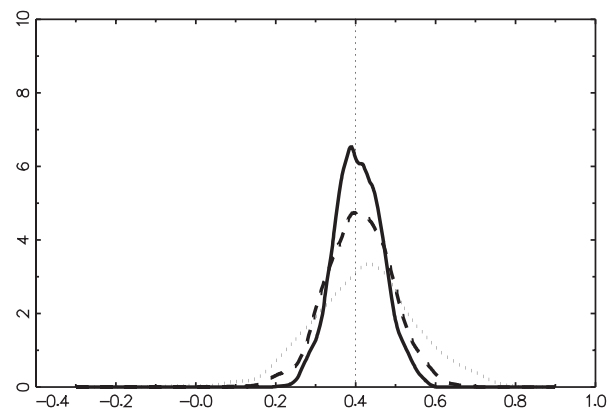

FIGURE 3

Monte Carlo kernel densities of the FVECM parameter estimates for $b=0.3$ (panel a) and $b=0.3$ (panel b). Vertical dotted lines represent the true values. Solid lines correspond to $T=2,000$, dashed lines to $T=1,000$, and dotted lines to $T=500$. 
the densities of the $\alpha$ estimates are far from symmetric, in particular when $T=500$. This is due to the presence of outliers in correspondence of values of $\hat{b}$ that are negative. Note that the skewness tends to zero when $T \rightarrow \infty$, and this is in accordance with the asymptotic results in Johansen and Nielsen (2011). These results suggest that the estimation of the FVECM parameter with Johansen and Nielsen (2011) method is highly reliable when the sample size is larger than 2000 and $d=b$ which is the case in the log-range analysis.

\section{BIBLIOGRAPHY}

Alizadeh, S., Brandt, M. W., \& Diebold, F. X. (2002). Range-based estimation of stochastic volatility models. The Journal of Finance, 57, 1047-1091.

Andersen, T., \& Bollerslev, T. (1998). Answering the skeptics: Yes, standard volatility models do provide accurate forecasts. International Economic Review, 39, 885-905.

Andersen, T. G., Bollerslev, T., Diebold, F. X., \& Ebens, H. (2001). The distribution of stock return volatility. Journal of Financial Economics, 61, 43-76.

Andersen, T. G., Bollerslev, T., Diebold, F. X., \& Labys, P. (2003). Modeling and forecasting realized volatility. Econometrica, 71, 579-625.

Bai, J., \& Perron, P. (2003). Computation and analysis of multiple structural change models. Journal of Applied Econometrics, 18(1), 1-22.

Baillie, R., Bollerslev, T., \& Mikkelsen, H. O. A. (1996). Fractionally integrated generalized autoregressive conditional heteroskedasticity. Journal of Econometrics, 74, 3-30.

Beran, J. (1994): Statistics for long-memory processes. London: Chapman \& Hall.

Bollerslev, T., \& Mikkelsen, H. O. (1996). Modeling and pricing long memory in stock market volatility. Journal of Econometrics, 73, 151-184.

Brandt, M. W., \& Diebold, F. X. (2006). A no-arbitrage approach to range-based estimation of return covariances and correlations. Journal of Business, 79, 61-73.

Brandt, M. W., \& Jones, C. S. (2006). Volatility forecasting with range-based egarch models. Journal of Business \& Economic Statistics, 24(4), 470-486.

Brenner, R. J., \& Kroner, K. F. (1995). Arbitrage, cointegration and testing the unbiasedbess hypothesis in financial markets. Journal of Financial and Quantitative Analysis, 30, 23-42.

Campbell, J. Y., \& Shiller, R. J. (1987). Cointegration and tests of present value models. Journal of Political Economy, 95, 1062-1088.

Cavaliere, G., Rahbek, A., \& Taylor, A. (2010). Cointegration rank testing under conditional heteroskedasticity. Econometric Theory, 26, 1719-1760.

Chen, W., \& Hurvich, C. (2009). Fractional cointegration. In T. G. Andersen, R. A. Davis, J.-P. Kreiss, and T. Mikosch (Eds.), Handbook of Time Series Econometrics (chap. 33, pp. 709-726). Berlin: Springer.

Chow, Y.-F., McAleer, M., \& Sequeira, J. (2000). Pricing of forward and futures contracts. Journal of Economic Surveys, 14, 215-253.

Christensen, B., \& Santucci de Magistris, P. (2010). Level shifts in volatility and the implied-realized volatility relation. Discussion paper, CREATES Research Paper, 2010-60, Aarhus University. 
Christoffersen, P. (1998). Evaluating interval forecasts. International Economic Review, 39, 841-862.

Corbae, D., \& Ouliaris, S. (1988). Cointegration and tests of purchasing power parity. The Review of Economics and Statistics, 70, 508-511.

Corsi, F. (2009). A simple approximate long-memory model of realized volatility. Journal of Financial Econometrics, 7, 174-196.

Cox, C. C. (1976). Futures trading and market information. The Journal of Political Economy, 84, 1215-1237.

Dacorogna, M., Muller, U. A., Nagler, R. J., Olsen, R. B., \& Pictet, O. V. (1993). A geographical model for the daily and weekly seasonal volatility in the foreign exchange market. Journal of International Money and Finance, 12, 413-438.

Davidson, J. (2002). A model of fractional cointegration, and tests for cointegration using the bootstrap. Journal of Econometrics, 110(2), 187-212.

Diebold, F. X., \& Mariano, R. S. (1995). Comparing predictive accuracy. Journal of Business \& Economic Statistics, 13(3), 253-263.

Ding, Z., Granger, C. W. J., \& Engle, R. F. (1993). A long memory property of stock market returns and a new model. Journal of Empirical Finance, 1, 83-106.

Duecker, M., \& Startz, R. (1998). Maximum likelihood estimation of fractional cointegration with an application to US and Canadian bond rates. Review of Economics and Statistics, 80, 420-426.

Dwyer, G. P., Locke, P. R., \& Yu, W. (1996). Index arbitrage and nonlinear dynamics between the S\&P 500 futures and cash. Review of Financial Studies, 9(1), 301-332.

Garman, M. B., \& Klass, M. J. (1980), On the estimation of security price volatilities from historical data. The Journal of Business, 53, 67-78.

Geweke, J., \& Porter-Hudak, S. (1984). The estimation and application of long memory time series models. Journal of Time Series Analysis, 4, 221-238.

Granger, C. W. J. (1986). Developments in the study of cointegrated economic variables. Oxford Bulletin of Economics and Statistics, 48(3), 213-228.

Granger, C. W. J., \& Ding, Z. (1996). Modeling volatility persistence of speculative returns. Journal of Econometrics, 73, 185-215.

Granger, C. W. J., \& Hyung, N. (2004). Occasional structural breaks and long memory with application to the S\&P 500 absolute stock returns. Journal of Empirical Finance, 11, 399-421.

Haldrup, N., Nielsen, F. S., \& Nielsen, M. (2010). A vector autoregressive model for electricity prices subject to long memory and regime switching. Energy Economics, 32, 1044-1058.

Hannan, E. J., \& Quinn, B. G. (1979). The determination of the order of an autoregression. Journal of the Royal Statistical Society, B, 41, 190-195.

Hosking, J. (1981). Fractional differencing. Biometrika, 68, 165-176.

Hualde, J., \& Robinson, P. (2010). Semiparametric inference in multivariate fractionally cointegrated systems. Journal of Econometrics, 157, 492-511.

Jacob, J., \& Vipul (2008). Estimation and forecasting of stock volatility with rangebased estimators. Journal of Futures Markets, 6, 561-581.

Johansen, S. (1991). Estimation and hypothesis testing of cointegration vectors in Gaussian Vector Autoregressive Models. Econometrica, 59(6), 1551-1580.

Johansen, S. (2008). A representation theory for a class of vector autoregressive models for fractional processes. Econometric Theory, 24, 651-676. 
Johansen, S., \& Nielsen, M. Ø. (2010). Likelihood inference for a nonstationary fractional autoregressive model. Journal of Econometrics, 158(1), 51-66.

Johansen, S., \& Nielsen, M. Ø. (2011). Likelihood inference for a fractionally cointegrated vector autoregressive model. Queen's Economic Department, working paper 1237.

Kupiec, N. (1995). Techniques for verifying the accuracy of risk measurement models. Journal of Derivatives, 3, 73-84.

Łasak, K. (2008). Maximum likelihood estimation of fractionally cointegrated systems. Discussion paper, CREATES Research Paper 2008-2053.

Mincer, J. A., \& Zarnowitz, V. (1969). The evaluation of economic forecasts. Nber working papers, National Bureau of Economic Research, Inc.

Nielsen, M. Ø., \& Shimotsu, K. (2007). Determining the cointegration rank in nonstationary fractional system by the exact local Whittle approach. Journal of Econometrics, 141, 574-596.

Palma, W. (2007). Long-memory time series: Theory and methods. Wiley series in probability and statistics. New York: Wiley.

Parkinson, M. (1980). The extreme value method for estimating the variance of the rate of return. The Journal of Business, 53, 61-65.

Patton, A. J. (2011). Volatility forecast comparison using imperfect volatility proxies. Journal of Econometrics, 160, 246-256.

Perron, P., \& Qu, Z. (2010). Long-memory and level shifts in the volatility of stock market return indices. Journal of Business \& Economic Statistics, 28(2), 275-290.

Pizzi, M. A., Economopoulos, A., \& O'Neill, H. M. (1998). An examination of the relationship between stock index cash and future market: A cointegration approach. Journal of Futures Markets, 18, 297-305.

Robinson, P. M., \& Yajima, Y. (2002). Determination of cointegrating rank in fractional systems. Journal of Econometrics, 106, 217-241.

Rogers, L., \& Satchell, S. (1991). Estimating variance from high, low and closing prices. Annals of Applied Probability, 1, 504-512.

Rossi, E., \& Spazzini, F. (2009). Finite sample results of range-based integrated volatility estimation. Discussion Paper WP-CEA-4-2009, Center for Econometric Analysis, Cass Business School.

Schwarz, G. E. (1978). Estimating the dimension of a model. Annals of Statistics, 6, 461-464.

Shimotsu, K., \& Phillips, P. (2005). Exact local Whittle estimation of fractional integration. Annals of Statistics, 33, 1890-1933.

Shou, J., \& Zhang, J. E. (2006). Testing range estimators of historical volatility. Journal of Futures Markets, 26, 297-313.

Sowell, F. (1989). Maximum likelihood estimation of fractionally integrated time series models. Discussion paper, unpublished manuscript Carnegie-Mellon University.

Sowell, F. (1992). Maximum likelihood estimation of stationary univariate fractionally integrated time series models. Journal of Econometrics, 53, 165-188.

Wiggins, J. B. (1992). Estimating the volatility of S\&P 500 Futures Prices using the extreme-value method. Journal of Futures Markets, 12, 265-274. 